\title{
Formulation of the Objective Function for Economic Dispatch Optimisation of Steam Cycle CHP Plants
}

\author{
Olegs Linkevics, non-member IEEE, and Antans Sauhats, Member IEEE
}

\begin{abstract}
The paper starts the series of publications concerned on production simulation and expansion planning of various cogeneration applications, especially based on distributed generation technologies. This particular paper presents the formulation of optimisation problem for economic dispatch of steam cycle CHP plants widely used in the former Soviet Union. Polynomial quadratic equations were applied to describe interrelations between input steam and output power and heat for cogeneration steam turbines. Mathematical model of turbines was verified by numerical example, taking the input data from normative characteristic graphs.
\end{abstract}

Index Terms-- CHP plants (cogeneration), economic dispatch, production simulation, quadratic equations, Lagrange-relaxation technique, Kuhn-Tucker conditions.

\section{INTRODUCTION}

$\mathrm{C}$ OGENERATION is a simultaneous production of two/three forms of energy in a single process. The advantage of cogeneration mainly comes from utilisation of energy, which during the separate power production is lost in condenser. According to the Directive 2004/8/EC [1] "Promotion of high-efficiency cogeneration based on a useful heat demand is a Community priority given the potential benefits of cogeneration with regard to saving primary energy, avoiding network losses and reducing emissions, in particular of greenhouse gases. It contribute positively to the security of energy supply and to the competitive situation of the European Union".

Some methods for calculation of power and heat output from cogeneration and definition of CHP efficiency criteria were developed to ensure a force of the Directive 2004/8/EC. The most comprehensive is so called ProTermo method [2]. It was primary developed for statistical data processing to provide "guarantees of origin of electricity from highefficiency cogeneration". At the same time, the Directive obliges Members States "to establish an analysis of the national potential for the application of high-efficiency cogeneration, including high-efficiency micro-cogeneration".

The research activity presented in this paper is supported by the European Union through the SES6-CT-2003-503516 project "EU-DEEP" and the European Social Fund.

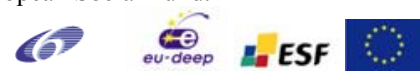

That is why production simulation and expansion planning of CHP plants is so important, especially for comparison of separate and combined production of energy.

Production simulation assumes unit commitment and economic dispatch. While unit commitment planning establishes, which unit will be on-line for each hour, unit dispatch planning determines the share of the load demand that each unit delivers. The purpose of economic unit dispatch is to minimise the total system operating cost for delivering energy to meet system load demand. Economic dispatch problem of CHP plants is more complicated problem comparison to power unit dispatch due to two-dimensional nature of the problem.

The authors have developed a set of polynomial quadratic equations to describe the cost function for CHP plants to be minimised.

The next issue of the research is an expansion of economic dispatch optimisation problem to consider probabilistic production simulation methods [3], [4] (to account for forced outage rates of generating units), multi-area production simulation and capacity expansion planning [5] for CHP plants. Both centralised and distributed cogeneration applications will be considered.

\section{Overview of COGENERATION TECHNOLOGIES}

Cogeneration plants could be classified as heating, industrial, agricultural or combinations of above.

Heating cogeneration is used in centralised, local or even individual heating systems. Main products of cogeneration plants are electricity, heat for space and water heating, cooling, conditioning, steam for industrial processes.

District heating loads typically have seasonal variations, while power loads are more volatile (with peak / off-peak hours) during the day. Very often heat and power load patterns does not coincide. In some periods cogeneration systems could have power excess (overflow or top-up energy), but in some - deficit (unserved or back-up energy) [3].

Electricity markets brought its impact on the manner of operation of cogeneration plants forcing them to operate in peak hours, when power system prices are the highest, and to accumulate heat in heat accumulators for discharge in offpeak hours. 
By size cogeneration could be divided for:

- Micro cogeneration (with capacity up to $50 \mathrm{~kW}$ ).

- Mini cogeneration (up to $1 \mathrm{MW}$ ).

- Average cogeneration (up to $50 \mathrm{MW}$ ).

- $\quad$ Big cogeneration (> $50 \mathrm{MW}$ ).

Micro and mini cogeneration systems are related to so called distributed (co)-generation. It could be isolated ( $\mu$ grid) or interconnected at distribution level.

Different technologies are used for cogeneration: combined cycle, steam backpressure turbine, steam condensing extraction turbine, gas turbine with heat recovery, internal combustion engine, microturbines, Stirling engines, fuel cells, steam engines, organic Rankine cycles. Some of these technologies are described in the TABLE I.

TABLE I

KEy INDICATORS OF DIFFERENT COGENERATION TECHNOLOGIES [2]

\begin{tabular}{|l|c|c|}
\hline Technologies & $\begin{array}{c}\text { Power to } \\
\text { heat ratio }\end{array}$ & Efficiency \\
\hline Internal combustion engine & $0.75-0.89$ & $84 \%-91 \%$ \\
\hline Gas turbine with heat recovery boiler & $0.55-0.58$ & $83 \%-91 \%$ \\
\hline Industrial backpressure turbines & 0.28 & $81 \%-87 \%$ \\
\hline Heating backpressure turbines & 0.52 & $83 \%-90 \%$ \\
\hline Steam condensing extraction turbine & $0.3-0.45$ & $41 \%-75 \%$ \\
\hline Combined cycle & $0.95-1.15$ & $84 \%-91 \%$ \\
\hline
\end{tabular}

Cogeneration plants may have single- or multi-fuel equipment, for example a combination of natural gas and heavy fuel oil. Different types of fuels might be used, such as gas, oil, coal, peat, biomass, etc. There were even attempts to build nuclear CHP plants.

Some CHP plants, in addition to combined power and heat equipment also have heat only boilers (HOB) and regular power generators.

Usually, the main objective of CHP plants is to satisfy heat load, while electricity is a by-product. However, in the modern market environment, sometimes happen vise-versa.

The efficiency of energy production in cogeneration plants depends greatly from the relationship between power and heat loads, number and type of equipment in operation, fuel type and operation mode.

\section{Matching Of CHP To Electricity And Heat Demand}

Usually shapes of demand curves for electrical power and heat are very different.

Heat demand curve of centralized district heating consumers is quite variable on seasonal basis. Fig. 1 illustrates variation of power and heat energy demand on example of Latvian power and Riga district heating systems [6]. In a summer, when space heating is switched off, average heat energy demand during a week could be approximately $10 \%$ $15 \%$ of maximum heat demand during the coldest week of the year. In average, during a heating period, weekly heat demand could be approximately $60 \%-70 \%$ of the coldest week's demand.
Variation between maximum and minimum power demand is not so great: usually during a summer minimum weekly energy demand is about $50-60 \%$ of power system maximum demand, but during spring and autumn average demand is approximately $70 \%-80 \%$ of maximum week's demand.

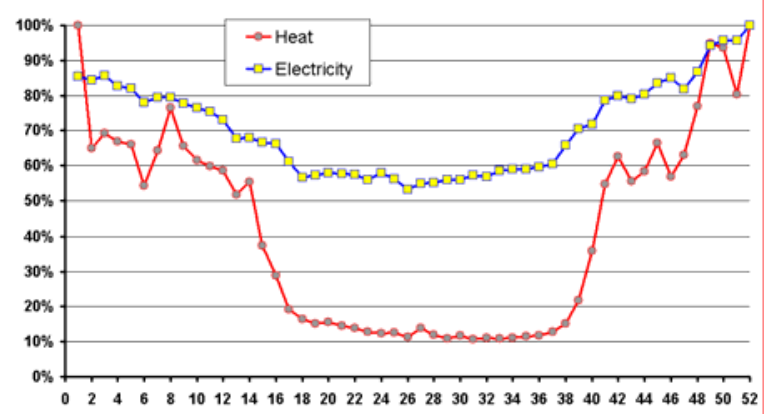

Fig. 1 Seasonal variations of electric and heat energy demand by week

At the same time during a day, the picture is totally different, observe it on the Fig. 2. Heat load demand is quite stable, changing in the range of $10 \%-20 \%$, whereas power demand is very fluctuating (up to $40 \%$ ).

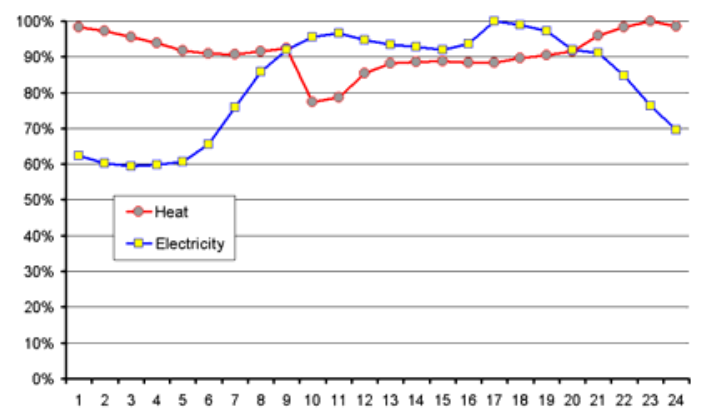

Fig. 2 Daily variations of electric and heat load demand

The above-mentioned graphs illustrate impossibility to satisfy consumer's power and heat demand by pure base-load CHP systems. Peak units, such as hydro or simple cycle gas turbines should be used during the day to balance power demand, whereas heat only boilers are operated at winter maximum heat loads. Otherwise, energy accumulating systems may be used to balance load fluctuations.

\section{CHOICE OF OPTIMAL CAPACITY OF COGENERATION PLANTS}

In principal there are several approaches how to determine heat capacity of cogeneration plant, as presented in Fig. 3:

- Based on average summer heat loads. In this case CHP is operated in cogeneration mode for at least 8000 hours and gain a highest possible economic efficiency.

- Based on average winter heat loads. In this case CHP is operated in cogeneration mode for 4000-5000 hours, having less attractive efficiency indicators, but higher production volumes.

- Based on peak heat loads. This approach is used, when CHP plant is operated in a competitive market. It assumes maximum production at power system peak hours (when prices are the highest) with accumulation 
of heat in heat accumulators.

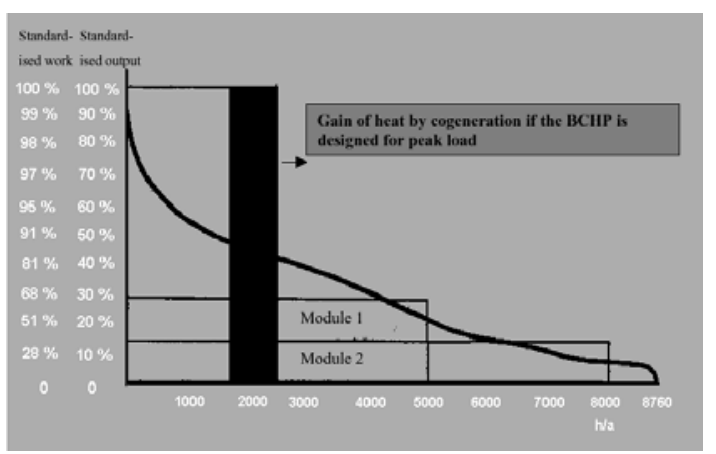

Fig. 3 Choice of optimal capacity of cogeneration plants [7]

\section{Formulation of The OBJECTIVE FunCTION}

For modeling purposes cogeneration systems may be decomposed into the principal components, that are steam generators (boilers), steam turbines, heat only boilers, gas turbines, heat recovery boilers.

Steam generators in CHP plant serve to supply steam to several steam turbines via common pipeline or to a single unit. Steam could be also supplied directly to steam or heat consumers through the pressure reducing and cooling equipment. Relationship between input fuel and output steam could be represented in linear or quadratic form.

Steam turbines installed in CHP plants are basically backpressure or condensing with steam extraction to industrial steam consumers and/or to district heating system. They have complex correlations between energy generation and apportioned steam consumption, depending from many parameters. These correlations are described by normative characteristic graphs. Such a detail model of steam turbine is not necessary for the purpose of longer-term planning. However it is important for real-time operations.

Major types of steam turbines, according to former Soviet Union classification are (Fig. 4):

- $\mathrm{C}(\mathrm{K})$ - Condensing turbine

- $\quad \mathrm{T}(\mathrm{T})$ - Condensing turbine with automatic extraction to district heating system

- $\quad \mathrm{P}(\Pi)$ - Condensing turbine with automatic extraction to industrial steam consumer

- PT (ПТ) - Condensing turbine with double automatic extraction: to industrial steam consumer and district heating system

- $\quad \mathrm{p}(\mathrm{P})$ - Backpressure (non-condensing) turbine

- $\mathrm{pP}(\Pi \mathrm{P})$ - Backpressure (non-condensing) turbine with automatic extraction to industrial steam consumer

Backpressure steam turbines could only operate in cogeneration mode. The relationship between heat and power capacity is practically linear.
Condensing turbines with extractions could operate in different modes:

- Cogeneration mode (simultaneous production of electricity and heat or industrial steam. Electricity in this case is by-product. The general purpose is to meet a heat/steam load).

- Condensing mode (production of electricity only, extractions are closed).

- Mixed cogeneration-condensing mode (production of electricity and heat or industrial steam partly in cogeneration, partly in condensing mode).
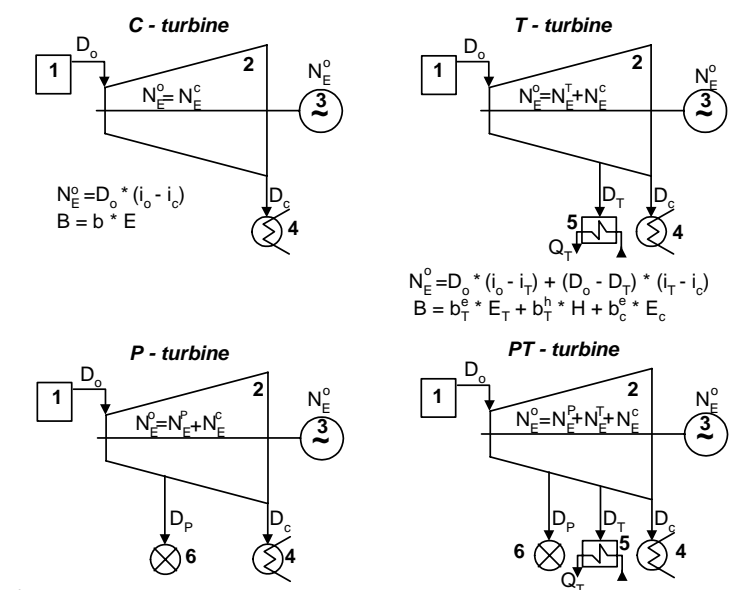

$N_{E}^{0}=D_{o}^{*}\left(i_{0}-i_{P}\right)+\left(D_{o}-D_{P}\right) *\left(i_{P}-i_{C}\right)$

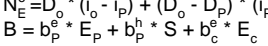

$N^{0}=D_{0}^{*} *\left(i_{0}-i_{P}\right)+\left(D_{0}-D_{P}\right) *\left(i_{P}-i_{T}\right)+\left(D_{0}-D_{p}-D_{T}\right) *\left(i_{T}-i_{P}\right)$

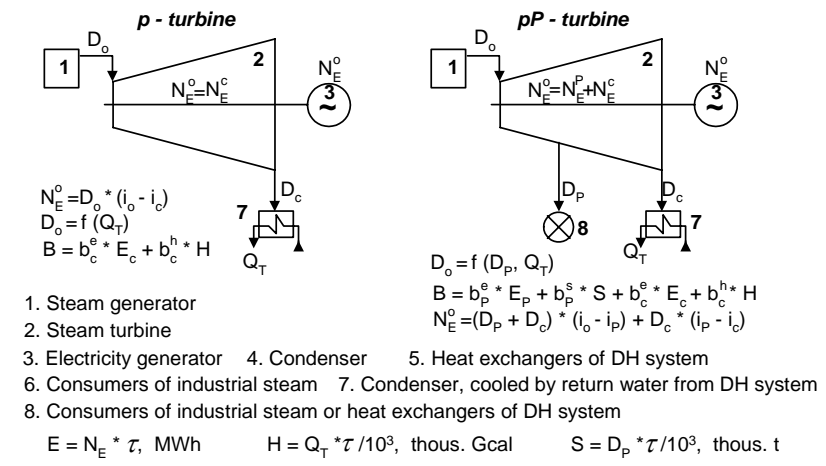

$B=b_{T}^{e} * E_{T}+b_{T}^{h} * H+b_{P}^{e} * E_{p}+b_{P}^{s *} S+b_{c}^{e} * E_{c}$

Fig. 4 Different types of Cogeneration steam turbines

Heat only boilers (HOB) are installed in some CHP plants to cover peak demand for heat or to serve as a backup capacity. Its mathematical model is very similar to those of steam generators.

Further, mathematical model of cogeneration system based on steam turbines will be derived. For the simplicity of the model, some details of steam turbine characteristic graphs, such as steam extraction to feed water heaters, difference of pressure in steam extraction will not be taken into account. 


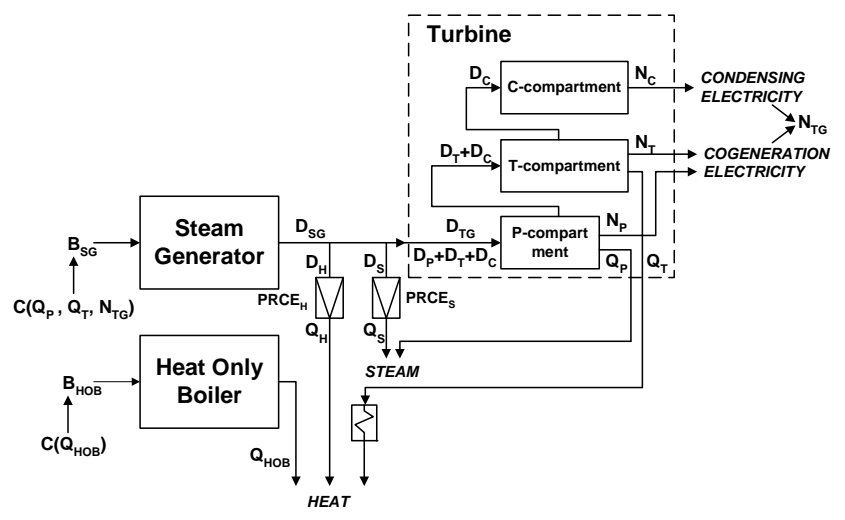

Fig. 5. Flowchart of cogeneration system

As in Fig. 5 PT-turbine could be represented as a sequential connection of two backpressure and one condensing turbine. With this method each turbine (or compartment) has its own correlation between input and output parameters, which is shown below:

- Correlation between turbine parameters:

P-compartment:

$$
\begin{aligned}
& D_{P}=\alpha_{0}+\alpha_{1} * Q_{P}+\alpha_{2} *\left(Q_{P}\right)^{2} \\
& N_{P}=\left[\beta_{0}+\beta_{1} * D_{P}+\beta_{2} *\left(D_{P}\right)^{2}\right] / 1000
\end{aligned}
$$

T-compartment:

$$
\begin{aligned}
& D_{T}=\gamma_{0}+\gamma_{1} * Q_{T}+\gamma_{2} *\left(Q_{T}\right)^{2} \\
& N_{T}=\left[\delta_{0}+\delta_{1} * D_{T}+\delta_{2} *\left(D_{T}\right)^{2}\right] / 1000
\end{aligned}
$$

C-compartment:

$$
N_{C}=\left(D_{C} \varepsilon_{1}-\varepsilon_{0}\right) / 1000
$$

where

$D_{i} \quad$ - steam consumption to compartment

$Q_{i} \quad$ - heat output from extraction

$N_{i}$ - electric output

$\alpha_{j}, \beta_{j}, \gamma_{j}, \delta_{j}, \varepsilon_{i}$ - equation coefficients

- Total steam consumption and gross electric capacity of a turbine:

$$
\begin{aligned}
& D_{T G}=D_{P}+D_{T}+D_{C} \\
& N_{T G}=N_{P}+N_{T}+N_{C}
\end{aligned}
$$

- Application of formulas (1) - (7) for different types of cogeneration steam turbines (Fig. 4):

\section{C-turbine:}

$$
\begin{aligned}
& D_{P}=0, N_{P}=0, D_{T}=0, N_{T}=0 ; \\
& D_{T G}=D_{C}, N_{T G}=N_{C}
\end{aligned}
$$

\section{T-turbine:}

$$
\begin{aligned}
& D_{P}=0, N_{P}=0 ; \\
& D_{T G}=D_{T}+D_{C}, N=N_{T}+N_{C} ;
\end{aligned}
$$

P-turbine:

$$
\begin{aligned}
& D_{T}=0, N_{T}=0 ; \\
& D_{T G}=D_{P}+D_{C}, N_{T G}=N_{P}+N_{C}
\end{aligned}
$$

PT-turbine:

$$
D_{T G}=D_{P}+D_{T}+D_{C}
$$$$
N_{T G}=N_{P}+N_{T}+N_{C} \text {; }
$$

p-turbine:

$$
\begin{aligned}
& D_{P}=0, N_{P}=0, D_{C}=0, N_{C}=0 ; \\
& D_{T G}=D_{T}, N_{T G}=N_{T} ;
\end{aligned}
$$

pP-turbine:

$$
\begin{aligned}
& D_{C}=0, N_{C}=0 ; \\
& D_{T G}=D_{P}+D_{T}, N_{T G}=N_{P}+N_{T} ;
\end{aligned}
$$

- $\quad$ Steam demand from steam generator:

$$
D_{S G}=\left(D_{T G}+D_{H}+D_{S}\right) C_{t f}
$$

where $C_{t f}$ - coefficient of thermal flow (1.03...1.05) $D_{H}, D_{S}$ - steam to pressure reducing \& cooling units

- Fuel consumption of steam generator:

$$
B_{S G}=\zeta_{0}+\zeta_{1} * D_{S G}+\zeta_{2} *\left(D_{S G}\right)^{2}
$$

- $\quad$ Cost function of cogeneration unit:

$C\left(Q_{P}, Q_{T}, N_{T G}\right)=B_{S G} * C_{F U E L}+C_{O \& M} * N_{T G}$

where $C_{F U E L}$ - cost of fuel

$C_{O \& M}$ - operation and maintenance cost of cogeneration unit related to electric output

- Fuel consumption of heat only boiler:

$B_{\mathrm{HOB}}=\eta_{0}+\eta_{1} * Q_{\mathrm{HOB}}+\eta_{2} *\left(Q_{\mathrm{HOB}}\right)^{2}$

- Cost function of heat only boiler:

$$
C\left(Q_{H O B}\right)=B_{H O B} * C_{F U E L}+C_{O \& M} * Q_{H O B}
$$

- The objective function is the sum of cost functions of cogeneration units, heat only boilers and conventional units of CHP plant:

$$
C=\sum_{x=1}^{n_{H O B}} C_{x}\left(Q_{H O B}^{x}\right)+\sum_{y=1}^{n_{C O G}} C_{y}\left(Q_{P, T}^{y}, N_{T G}^{y}\right)+\sum_{z=1}^{n_{C O N D}} C_{z}\left(N_{C}^{z}\right)
$$

The purpose of optimisation is to minimize the objective function, while the heat / steam / power demands are met.

- Global constraints of optimisation task:

$$
Q_{H}=\sum_{y=1}^{n_{C O G}} Q_{P, T}^{y}+\sum_{x=1}^{n_{H O B}} Q_{H O B}^{x}
$$

where $Q_{H}-$ heat demand of CHP plant net of heat losses

$$
N_{E}=\sum_{y=1}^{n_{C O G}} N_{T G}^{y}+\sum_{z=1}^{n_{C O N D}} N_{C}^{z}
$$

where $N_{E}$ - electricity demand of CHP plant net of losses.

The above-mentioned constraints could be complicated by simulation of power and heat transmission/distribution losses. However, in generation planning approximation is usually made to reduce computer simulation costs [11]. 
- Local constraints of optimisation task (minimum and maximum capacity of each unit):

$$
\begin{aligned}
& Q_{P, T}^{\min } \leq Q_{P, T} \leq Q_{P, T}^{\max } \\
& N_{T G}^{\min } \leq N_{T G} \leq N_{T G}^{\max } \\
& Q_{H O B}^{\min } \leq Q_{H O B} \leq Q_{H O B}^{\max } \\
& N_{C}^{\min } \leq N_{C} \leq N_{C}^{\max }
\end{aligned}
$$

- Using LaGrange Multiplier for (14), (15) and KuhnTucker approach for (16)-(19), equation (13) could be transformed into the form called the LaGrange function of optimisation problem as in [9]:

$$
\begin{aligned}
& F=\sum_{x=1}^{n_{H O B}} C_{x}\left(Q_{H O B}^{x}\right)+\sum_{y=1}^{n_{C O G}} C_{y}\left(Q_{P, T}^{y}, N_{T G}^{y}\right)+\sum_{z=1}^{n_{C O N D}} C_{z}\left(N_{C}^{z}\right) \\
& +\lambda_{N}\left(N_{E}-\sum_{y=1}^{n_{C O G}} N_{T G}^{y}-\sum_{z=1}^{n_{C O N D}} N_{C}^{z}\right)+\lambda_{Q}\left(Q_{H}-\sum_{y=1}^{n_{C O G}} Q_{P, T}^{y}-\sum_{x=1}^{n_{H O B}} Q_{H O B}^{z}\right) \\
& +\sum_{z=1}^{n_{C O N D}} \mu_{z} N_{C}^{z}+\sum_{y=1}^{n_{C O G}}\left\{\mu_{y}^{N}\left[N_{T G}^{y}-N_{T G}^{m}\right]+\mu_{y}^{Q}\left[Q_{P, T}^{y}-Q_{P, T}^{m}\right]\right\}+\sum_{x=1}^{n_{H O B}} \mu_{x} Q_{H O B}^{x}
\end{aligned}
$$

where

$\lambda_{N}, \lambda_{Q}$ - respectively power and heat marginal costs.

$\mu_{z}, \mu_{x}$ - respectively power (C-turbine) and heat (HOB) unit capacity constraint multiplier.

$\mu_{y}^{N}, \mu_{y}^{Q}$ - heat-power feasible region constraints.

In [10] the LaGrange function was extended to include environmental constraints.

By differentiating $\mathrm{F}$ with respect to $\mathrm{N}_{\mathrm{TG}}, \mathrm{N}_{\mathrm{C}}, \mathrm{Q}_{\mathrm{P}, \mathrm{T}}, \mathrm{Q}_{\mathrm{HOB}}$ the first order Kuhn-Tucker conditions (optimal conditions of the problem) could be obtained.

$$
\begin{aligned}
& \frac{\partial F}{\partial N_{C}^{z}}=\frac{\partial C_{z}\left(N_{C}^{z}\right)}{\partial N_{C}^{z}}-\lambda_{N}+\mu_{z}=0 \\
& \frac{\partial F}{\partial N_{T G}^{y}}=\frac{\partial C_{y}\left(Q_{P, T}^{y}, N_{T G}^{y}\right)}{\partial N_{T G}^{y}}-\lambda_{N}+\mu_{y}^{N}-\mu_{y}^{Q} \frac{\partial Q_{P, T}^{m}}{\partial N_{T G}^{y}}=0 \\
& \frac{\partial F}{\partial Q_{P, T}^{y}}=\frac{\partial C_{y}\left(Q_{P, T}^{y}, N_{T G}^{y}\right)}{\partial Q_{P, T}^{y}}-\lambda_{Q}+\mu_{y}^{Q}-\mu_{y}^{N} \frac{\partial N_{T G}^{m}}{\partial Q_{P, T}^{y}}=0 \\
& \frac{\partial F}{\partial Q_{H O B}^{x}}=\frac{\partial C_{x}\left(Q_{H O B}^{x}\right)}{\partial Q_{H O B}^{x}}-\lambda_{Q}+\mu_{x}=0
\end{aligned}
$$

where

$\frac{\partial Q_{P, T}^{m}}{\partial N_{T G}^{y}} \quad$ - unit heat capacity incremental rate

$\frac{\partial N_{T G}^{m}}{\partial Q_{P, T}^{y}} \quad$ - unit power capacity incremental rate

\section{NUMERICAL EXAMPLE}

Mathematical model of turbine T-110/120-130 was verified by numerical example, taking the input data from normative characteristic graph (Fig. 6). The y-axis of the normative characteristic chart represents steam consumption to turbine $\left(D_{T G}\right)$, positive part of x-axis (I quadrant) represents electric output $\left(N_{T G}\right)$ of the turbine, negative part of $\mathrm{x}$-axis (II quadrant) is heat output from extraction $\left(Q_{T}\right)$.

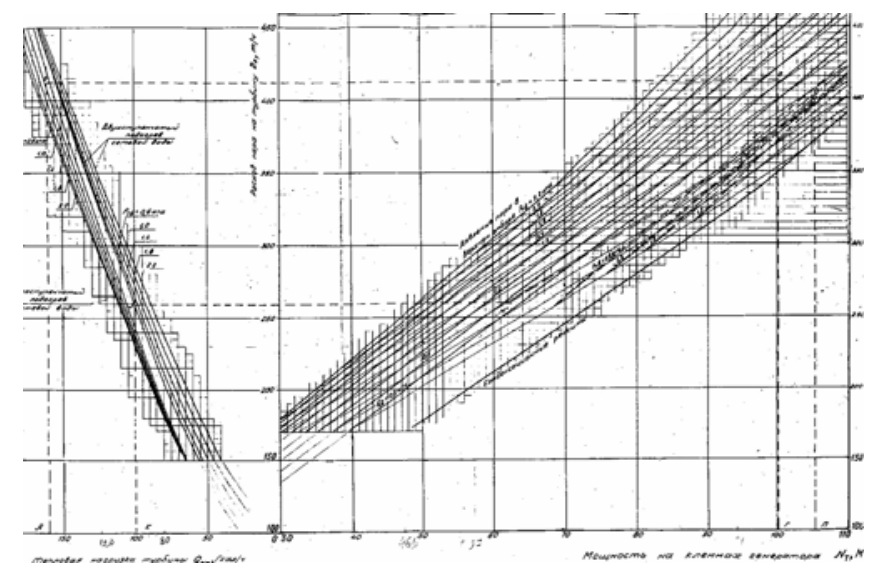

Fig. 6 Normative characteristic graphs of steam turbine T-110/120-130

Turbine T-110/120-130 is used as an example to model T-turbine. Mentioned turbine is condensing turbine with automatic extraction to district heating system.

Equations (3)-(7) for T-turbine are used in this example. First of all, coefficients of polynomial quadratic equations $\gamma_{j}$, $\delta_{j}$ and $\varepsilon_{j}$ will be found. Input data is collected from the characteristic graph (Table II).

TABLE II

INPUT DATA FOR CALCULATION OF COEFFICIENTS

\begin{tabular}{|c|c|c|}
\hline$D_{T}(t / h)$ & $N_{T}(M W)$ & $Q_{T}($ toe $/ h)$ \\
\hline 185 & 40 & 8 \\
\hline 225 & 45 & 12 \\
\hline 252 & 50 & 15 \\
\hline & & \\
\hline$D_{T G}(t / h)$ & $N_{T G}(M W)$ & $Q_{T}($ toe $/ h)$ \\
\hline 410 & 100 & 16 \\
\hline 310 & 70 & 16 \\
\hline
\end{tabular}

Applying the data from the table above into the formula (3), we have the system of equations:

$185=\gamma_{0}+\gamma_{1} * 8+\gamma_{2} *(8)^{2}$

$225=\gamma_{0}+\gamma_{1} * 12+\gamma_{2} *(12)^{2}$

$252=\gamma_{0}+\gamma_{1} * 15+\gamma_{2} *(15)^{2}$

Solving the simultaneous equations for $\gamma_{0}, \gamma_{1}, \gamma_{2}$ we obtain the coefficients. The summary of calculated coefficients is given in the (Table III). 
TABLE III

CALCULATED COEFFICIENTS

\begin{tabular}{|c|c|c|}
\hline$\gamma_{0}$ & $\gamma_{1}$ & $\gamma_{2}$ \\
\hline 91.28573 & 12.85714 & -0.142857 \\
\hline$\delta_{0}$ & $\delta_{1}$ & $\delta_{2}$ \\
\hline 54266.15475 & -243.29726 & 0.89829 \\
\hline$\varepsilon_{0}$ & $\varepsilon_{1}$ & \\
\hline-3299.49 & 300 & \\
\hline
\end{tabular}

To validate the mathematical model the real data from the characteristic graph will be compared with calculated.

From the characteristic graph we have:

$$
\begin{aligned}
& D_{T G}=290 \mathrm{t} / \mathrm{h} \\
& N_{T G}=70 \mathrm{MW} \\
& Q_{T}=12 \mathrm{toe} / \mathrm{h}
\end{aligned}
$$

Solving equation (3) we have:

$D_{T}=91.28573+12.85714 * 12-0.142857 *(12)^{2}=225 \mathrm{t} / \mathrm{h}$

By equation (4):

$$
\begin{aligned}
& N_{T}=\left[54266.15475-243.29726 * 225+0.89829 *(225)^{2}=\right. \\
& =45 \mathrm{MW}
\end{aligned}
$$

Based on equation (5):

$N_{c}=(300 * 65+3299.49)=22.8 \mathrm{MW}$

Using equation (7):

$N_{T G}=45+22.8=67.8 \mathrm{MW}$

Comparing calculated 67.8 MW with 70 MW from the characteristic graph, we found that the error is about $3 \%$.

\section{CONCLUSIONS}

Developed mathematical model of cogeneration turbines was implemented in the trial version of UPLAN Cogeneration Model [13], [14], [15].

\section{REFERENCES}

[1] Directive 2004/8/EC of the European parliament and of the Council of 11 February 2004 on the promotion of cogeneration based on a useful heat demand in the internal energy market and amending Directive 92/42/EEC.

[2] Manual for calculating CHP electricity and heat, Protermo Oy, 2000.

[3] C. Sondergren, H. F. Ravn "A method to perform probabilistic production simulation involving combined heat and power units", IEEE Transactions on Power Systems, Vol. 11, No. 2, 1996.

[4] G. Gross, N. V. Garapic, B. McNutt "The mixture of normals approximation technique for equivalent load duration curves", IEEE/PES 1986 Summer Meeting, Mexico City.

[5] N. Levin, J. Zahavi "Optimal mix algorithms with existing units", IEEE/PES 1983 Summer Meeting, Los Angeles, California, 1983.

[6] Power and heat load data of Latvenergo.

[7] Dr. D. Attig "New design criteria of CHP plants in liberalised markets," Power-Gen Europe 1999.

[8] F. J. Rooijers, R. A. M. van Amerongen, "Static economic dispatch for co-generation systems", IEEE Transactions on Power Systems, Vol. 9, No. 3, 1994.

[9] T. Guo, M. I. Henwood, M. van Ooijen, "An algorithm for combined heat and power economic dispatch", IEEE Transactions on Power Systems, Vol. 11, No. 4, 1996.

[10] R. M. Rifaat, "Economic dispatch of combined cycle cogeneration plants with environmental constraints", IEEE Catalogue, 0-7803-4495-2/98, 1998.

[11] H. G. Stoll, "Least-cost electric utility planning", book John Willey \& Sons, chapter 12: Production simulation, 1989

[12] M. Sudhakaran, S. M. R. Slochanal, "Integrating Genetic Algorithms and Tabu Search for combined heat and power economic dispatch", IEEE Catalogue, 0-7803-7651-X/03, 2003.

[13] O. Linkevics, N. Petrova, T. Ovsjukova "Modelling of combined heat and power plants", theoretical basis for modification of UPLAN's Cogeneration model, Riga, 1998.

[14] T.X. Zheng "Mathematical models for cogeneration turbines", Los Altos, California, 1996.

[15] UPLAN Cogeneration model. Reference manual, LCG Consulting, 1996.

This is a post-print of a paper published in 2005 IEEE Russia Power Tech Proceedings

[http://dx.doi.org/10.1109/PTC.2005.4524709] and is subject to IEEE copyright. 